\title{
Cellular Immunotherapies for Multiple Myeloma: Current Status, Challenges, and Future Directions
}

Zhi-Ling Yan · Yue-Wen Wang · Ying-Jun Chang

Received: December 4, 2021 / Accepted: January 20, 2022 / Published online: February 1, 2022

(C) The Author(s) 2022

\begin{abstract}
Multiple myeloma (MM) remains incurable due to relapse, although the use of proteasome inhibitors, immunomodulatory drugs, CD38targeting antibodies, and autologous stem cell transplantation (auto-SCT) significantly improve the clinical outcomes of patients with newly diagnosed MM. In recent years, the introduction of chimeric antigen receptor T-cell
\end{abstract}

Z.-L. Yan

Deparment of Hematology, The Affiliated Hospital of Xuzhou Medical University, Xuzhou, China

Y.-W. Wang · Y.-J. Chang ( $ه)$

Peking University People's Hospital \& Peking

University Institute of Hematology, No 11

Xizhimen South Street, Beijing 100044, China

e-mail: rmcyj@bjmu.edu.cn

Y.-W. Wang · Y.-J. Chang

National Clinical Research Center for Hematologic

Disease, Beijing, China

Y.-W. Wang · Y.-J. Chang

Beijing Key Laboratory of Hematopoietic Stem Cell

Transplantation, Beijing, China

Y.-W. Wang · Y.-J. Chang

Collaborative Innovation Center of Hematology,

Peking University, Beijing, People's Republic of

China
(CAR T-cell) therapy has brought hope to patients with refractory and relapsed MM. The graft-versus-myeloma effect of allogeneic SCT provides the possibility for curing a subset of MM patients. In this review, we summarize the recent advances and challenges of cellular immunotherapies for MM, focusing on autoSCT, allogeneic SCT, and CAR T-cell approaches. We also discuss future directions, and propose a specific algorithm for cellular therapies for MM and probability of minimal residual disease-directed therapy.

Keywords: Multiple myeloma; Autologous stem cell transplantation; Allogeneic stem cell transplantation; Chimeric antigen receptor $\mathrm{T}$ cell; Relapse 


\section{Key Summary Points}

Autologous stem cell transplantation (auto-SCT) remains the standard of care for transplant-eligible patients with newly diagnosed multiple myeloma.

Chimeric antigen receptor T-cell (CAR T-cell) therapy has been successfully used for the treatment of refractory/relapsed (R/R) Multiple myeloma (MM). The preliminary results of CAR T-cell bridging to SCT for patients with R/R MM are promising.

Long-term follow-up suggests that allogeneic SCT can provide an opportunity for curing a subset of MM patients.

In the era of new targeted therapies, minimal residual disease-directed treatment or intervention represents an important step for realizing precision medicine in patients with MM.

\section{INTRODUCTION}

Multiple myeloma (MM) is the second most common hematologic malignancy, responsible for 98,437 deaths globally in 2016 [1-5]. At present, patients with MM cannot be cured $[2,3,5,6]$, although the clinical use of immunomodulatory drugs (IMiD), proteasome inhibitors, cluster of differentiation 38 (CD38)targeting antibodies, and autologous stem cell transplantation (auto-SCT) has significantly extended survival time [1, 7-13]. In recent years, the introduction of chimeric antigen receptor T-cell (CAR T-cell) therapy has improved the prognosis of refractory and relapsing MM (R/R-MM) [6, 14-25]. Moreover, long-term follow-up has offered preliminary evidence that the existence of the graft-versusmyeloma effect after allogeneic SCT (allo-SCT) can improve outcomes and provide the possibility for curing a subset of patients with newly diagnosed MM (NDMM) [26-34]. Herein, we discuss the recent advances and challenges of cellular immunotherapies for $\mathrm{MM}$, focusing mainly on auto-SCT, allo-SCT, and CAR T-cell approaches (Tables 1, 2, and 3). We provide an outlook on future prospects and challenges in cellular therapy and note that dealing with relapse [35], minimal residual disease (MRD)directed therapy [7, 36-39], and combinations of different cellular therapy methods are active research areas in terms of improving prognosis for MM patients. This article is based on previously conducted studies and does not contain any new studies with human participants or animals performed by any of the authors.

\section{CURRENT STATUS}

\section{Auto-SCT}

\section{Auto-SCT for Patients with NDMM}

In the era of targeted therapies such as BCMACD3 bispecific antibody, CAR natural killer (NK) cells, belantamab mafodotin, and venetoclax, auto-SCT remains the standard of care for transplant-eligible (TE) patients with NDMM (Table 1) $[4,5,9,10,12,13,40-62]$.

Induction Therapy Current guidelines [2-4] recommend triplet regimens as induction therapy (IT) for TE patients with the addition of an IMiD, such as bortezomib, lenalidomide, and dexamethasone (VRD), bortezomib, thalidomide, and dexamethasone (VTD), and carfilzomib, lenalidomide, and dexamethasone (KRD), which are preferred to cyclophosphamide-containing regimens such as bortezomib, cyclophosphamide, and dexamethasone (VCD), and carfilzomib, cyclophosphamide, and dexamethasone (KCD).

In a recent study, $270 \mathrm{TE}$ patients with NDMM were randomized 1:1 to daratumumab (DARA) plus RVD (D-RVD) and RVD groups [45]. The authors observed a higher stringent complete response (sCR) rate for cases in the D-RVD group than that for cases in the RVD group (42.4\% vs. $32.0 \%$; one-sided $P=0.068$ ) by the end of post-auto-SCT consolidation. After a 
Table 1 Recent studies on the outcomes of MM patients who received autologous stem cell transplantation

\begin{tabular}{|c|c|c|c|c|c|c|}
\hline Author, year, Ref & $\begin{array}{l}\text { No. } \\
\text { Pts. }\end{array}$ & $\begin{array}{l}\text { Age } \\
(\mathbf{M})\end{array}$ & Diagnosis & Treatment modality & $\begin{array}{l}\text { Maintenance after } \\
\text { transplant }\end{array}$ & PFS \\
\hline \multirow[t]{3}{*}{ Gay et al. $2021[60]$} & 158 & 57 & NDMM & KRD + auto-SCT & $\mathrm{KR}$ or $\mathrm{R}$ alone & 4 years $69 \%$ \\
\hline & 157 & 57 & NDMM & KRD12 & $\mathrm{KR}$ or $\mathrm{R}$ alone & 4 years $56 \%$ \\
\hline & 159 & 57 & NDMM & $\mathrm{KCD}+$ auto-SCT & $\mathrm{KR}$ or $\mathrm{R}$ alone & 4 years $51 \%$ \\
\hline \multirow{2}{*}{$\begin{array}{l}\text { Moreau et al. } 2021 \\
\text { [12] }\end{array}$} & 543 & 59 & NDMM & D-VTD + auto-SCT & DARA or obser & 1.5 years $93 \%$ \\
\hline & 542 & 58 & NDMM & VTD + auto-SCT & DARA or obser & 1.5 years $85 \%$ \\
\hline \multirow[t]{2}{*}{$\begin{array}{l}\text { Jackson et al. } 2021 \\
\text { [53] }\end{array}$} & 1021 & 61 & NDMM & CRD + auto-SCT & $\begin{array}{l}\mathrm{R} \text { or } \mathrm{R} \text { and vorinostat } \\
\text { or obser }\end{array}$ & 36.00 months \\
\hline & 1021 & 61 & NDMM & CTD + auto-SCT & $\begin{array}{l}\mathrm{R} \text { or } \mathrm{R} \text { and vorinostat } \\
\text { or obser }\end{array}$ & 33.00 months \\
\hline \multirow[t]{2}{*}{$\begin{array}{l}\text { Usmani et al. } 2021 \\
\text { [10] }\end{array}$} & 52 & 66 & $\begin{array}{l}\text { HR- } \\
\text { NDMM }\end{array}$ & RVD + auto-SCT & RVD & 33.64 months \\
\hline & 48 & 62 & $\begin{array}{l}\text { HR- } \\
\text { NDMM }\end{array}$ & $\begin{array}{l}\text { RVD- } \\
\text { elotuzumab + auto- } \\
\text { SCT }\end{array}$ & RVD + elotuzumab & 31.47 months \\
\hline \multirow[t]{2}{*}{$\begin{array}{l}\text { Goldschmidt et al. } \\
2021 \text { [61] }\end{array}$} & 139 & 61.3 & R-MM & $\mathrm{RD}+$ auto-SCT & $\mathrm{R}$ & 20.70 months \\
\hline & 138 & 61.2 & R-MM & $\mathrm{RD}$ & $\mathrm{RD}$ & 18.80 months \\
\hline \multirow[t]{3}{*}{ Mai et al. 2021 [55] } & 353 & $\begin{array}{r}\leq 60 \\
(S 1)\end{array}$ & NDMM & Tandem auto-SCT & $\mathrm{R}$ & $\mathrm{N} / \mathrm{A}$ \\
\hline & 107 & $\begin{array}{r}61-65 \\
(S 2)\end{array}$ & NDMM & Tandem auto-SCT & $\mathrm{R}$ & $\begin{array}{l}\text { HR 1.28; } \\
\qquad P=0.11\end{array}$ \\
\hline & 141 & $\begin{array}{r}66-70 \\
(\mathrm{~S} 3)\end{array}$ & NDMM & Tandem auto-SCT & $\mathrm{R}$ & $\begin{array}{l}\text { HR 1.00; } \\
P=0.99\end{array}$ \\
\hline \multirow[t]{2}{*}{$\begin{array}{l}\text { Baertsch et al. } 2021 \\
\quad[46]\end{array}$} & 138 & 56 & NDMM & $\begin{array}{l}\text { BTZ-based triplet } \\
\text { IT + auto-SCT }\end{array}$ & $\mathrm{BTZ}$ & $\mathrm{N} / \mathrm{A}$ \\
\hline & 183 & 57 & NDMM & $\begin{array}{l}\text { BTZ-based triplet } \\
\text { IT + auto-SCT }\end{array}$ & $\mathrm{R}$ & $\begin{array}{l}\mathrm{HR} 0.83 \\
\qquad P=0.18\end{array}$ \\
\hline \multirow[t]{2}{*}{$\begin{array}{l}\text { Gregersen et al. } 2021 \\
\text { [51] }\end{array}$} & 82 & 60 & R-MM & $\mathrm{KCD}+$ auto-SCT & $\mathrm{KD}$ & 25.10 months \\
\hline & 86 & 62 & R-MM & $\mathrm{KCD}+$ auto-SCT & Placebo & 16.70 months \\
\hline \multirow{2}{*}{$\begin{array}{l}\text { Jackson et al. } 2021 \\
\qquad[52,53]\end{array}$} & 526 & 61 & NDMM & $\mathrm{KRDc}$ & $\mathrm{R}$ or obser & 3 years $81.8 \%$ \\
\hline & 530 & 62 & NDMM & $\mathrm{RDc} / \mathrm{TDc}$ & R or obser & 3 years $75.1 \%$ \\
\hline
\end{tabular}


Table 1 continued

\begin{tabular}{|c|c|c|c|c|c|c|}
\hline Author, year, Ref & $\begin{array}{l}\text { No. } \\
\text { Pts. }\end{array}$ & $\begin{array}{l}\text { Age } \\
(\mathbf{M})\end{array}$ & Diagnosis & Treatment modality & $\begin{array}{l}\text { Maintenance after } \\
\text { transplant }\end{array}$ & PFS \\
\hline \multirow{2}{*}{$\begin{array}{l}\text { Voorhees et al. } 2020 \\
\text { [45] }\end{array}$} & 104 & 59 & NDMM & D-RVD + auto-SCT & $\mathrm{R}$ or $\mathrm{R}$ and DARA & 2 years $95.8 \%$ \\
\hline & 103 & 61 & NDMM & RVD + auto-SCT & $\mathrm{R}$ or $\mathrm{R}$ and DARA & 2 years $89.8 \%$ \\
\hline \multirow{2}{*}{$\begin{array}{l}\text { Tacchetti et al. } 2020 \\
\text { [9] }\end{array}$} & 241 & 56.3 & NDMM & VTD + auto-SCT & DEX & 10 years $34 \%$ \\
\hline & 239 & 55.9 & NDMM & $\mathrm{TD}+$ auto-SCT & DEX & 10 years $17 \%$ \\
\hline \multirow{2}{*}{$\begin{array}{l}\text { Dimopoulos et al. } \\
2019 \text { [66] }\end{array}$} & 395 & 58 & NDMM & Auto-SCT & Ixazomib & 26.50 months \\
\hline & 261 & 60 & NDMM & Auto-SCT & Placebo & 21.30 months \\
\hline
\end{tabular}

$M M$ multiple myeloma, Ref reference, Pts. patients, No. number, $M$ median, $P F S$ progression-free survival, $N D M M$ newly diagnosed MM, $R-M M$ relapsed MM, $K R D$ carfilzomib, lenalidomide, dexamethasone, $K R$ carfilzomib, lenalidomide, $R$ lenalidomide, auto-SCT autologous stem cell transplantation, $K C D$ carfilzomib, cyclophosphamide, dexamethasone, $D$ $V T D$ daratumumab, bortezomib, thalidomide, dexamethasone, DARA daratumumab, CRD cyclophosphamide, lenalidomide, dexamethasone, CTD cyclophosphamide, thalidomide, dexamethasone, HR-NDMM high-risk NDMM, RVD (VRD) bortezomib, lenalidomide, dexamethasone, $R D$ lenalidomide, dexamethasone, $B T Z$ bortezomib, $I T$ induction therapy, obser observation, $K D$ carfilzomib, dexamethasone, $K R D c$ carfilzomib, lenalidomide, dexamethasone, and cyclophosphamide, $R D c$ lenalidomide, dexamethasone, and cyclophosphamide, $T D c$ thalidomide, dexamethasone, and cyclophosphamide, $D E X$ dexamethasone

median follow-up of 22.1 months, the sCR rates (62.6\% vs. $45.4 \% ; P=0.0177)$ and MRD negativity $\left(10^{-5}\right.$ threshold) rates $(51.0 \%$ vs. $20.4 \%$; $P<0.0001)$ were further improved. Recent updated data showed that the estimated 36-month progression-free survival (PFS) rate was $88.9 \%$ and $81.2 \%$ for the D-RVD group and RVD group, respectively. Subgroup analysis showed the superiority of DARA and lenalidomide over placebo for maintenance. These results support the use of D-RVD, DARA, and lenalidomide in TE NDMM patients.

In the randomized, open-label, phase 3 CASSIOPEIA trial, Moreau et al. [63] first demonstrated the clinical benefit of DARA plus standard of care in TE patients with NDMM, including a better sCR rate (D-VTD 29\% vs. VTD $20 \%, P=0.0010)$, a better MRD negativity rate (D-VTD $64 \%$ vs. VTD $44 \%, P<0.0001$ ), and a longer median PFS from the first randomization (hazard ratio 0.47, $P<0.0001$ ). Roussel et al. [8] further reported the clinical benefits observed with D-VTD versus VTD, both of which supported the addition of DARA to standard regimens in patients with NDMM. The benefits of adding DARA to RD led to increased overall survival (OS) and PFS in patients with NDMM ineligible for auto-SCT [11]. In a phase III trial, Goldschmidt et al. [64] for the first time observed that, compared with RVd, RVd with the anti-CD38 monoclonal antibody (CD38moAb) isatuximab was associated with higher MRD negativity after IT in TE patients with NDMM.

Overall, for TE patients with NDMM, the aim of IT was to achieve maximal response with four to six cycles of therapy before auto-SCT. The European Medicines Agency has approved D-VTD as a new standard of care for IT pre-autoSCT for patients with TE NDMM [2-4]. Therefore, in the near future, quadruplet regimens such as D-RVD and isatuximab + VRD might be accepted as novel standard approaches.

Conditioning Regimen In a recent study by Bashir et al. [65], 205 patients were randomly 


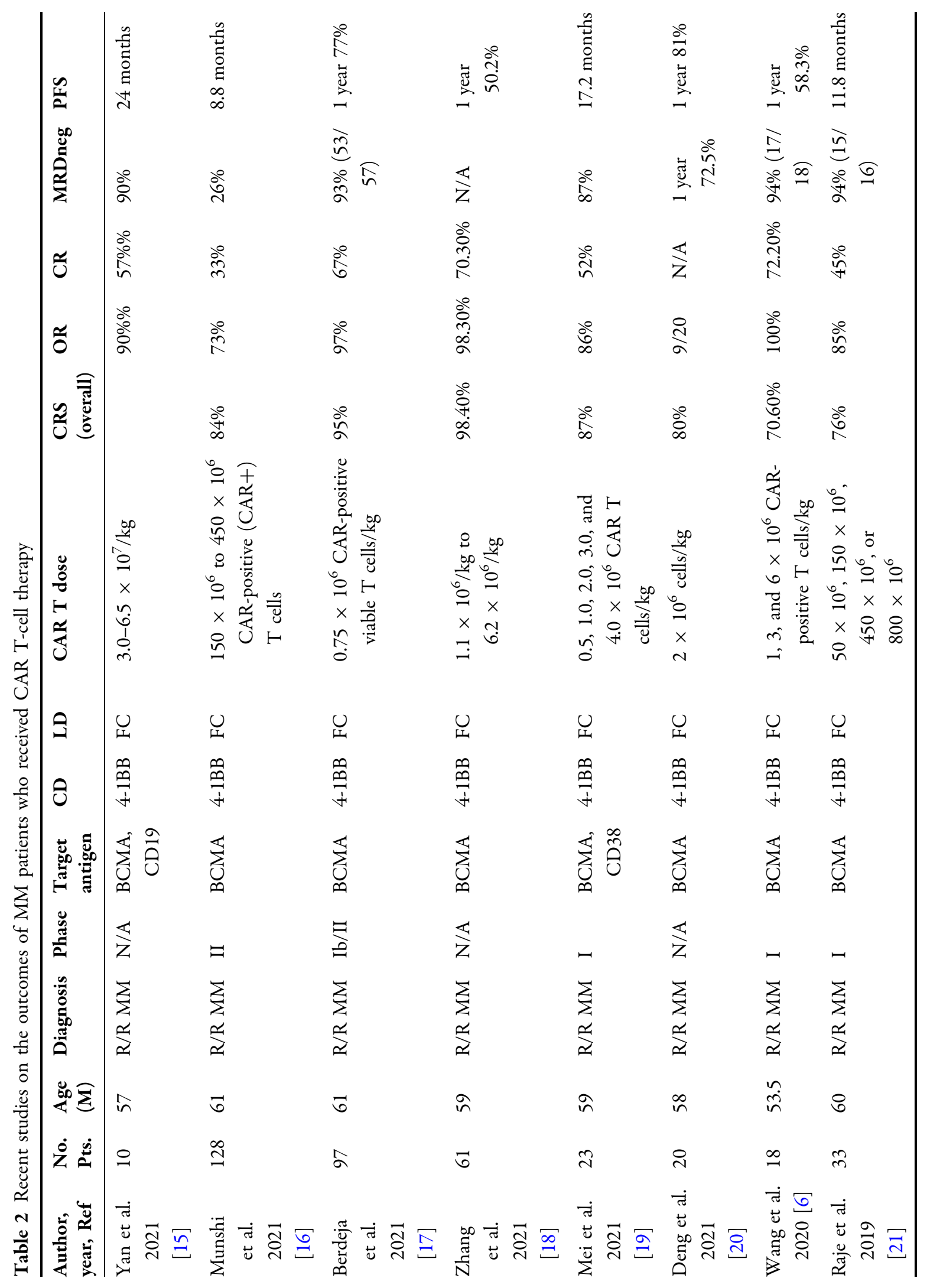




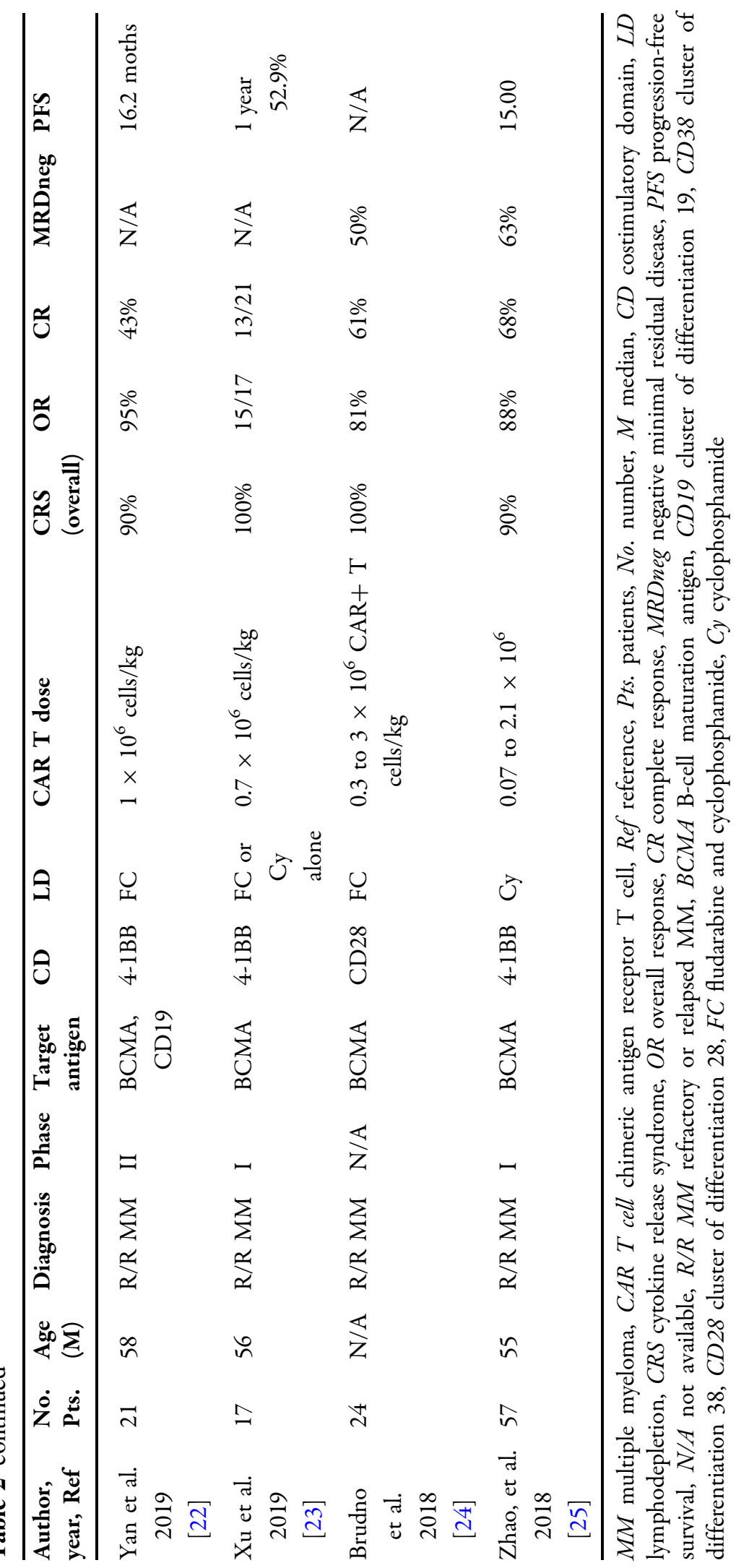




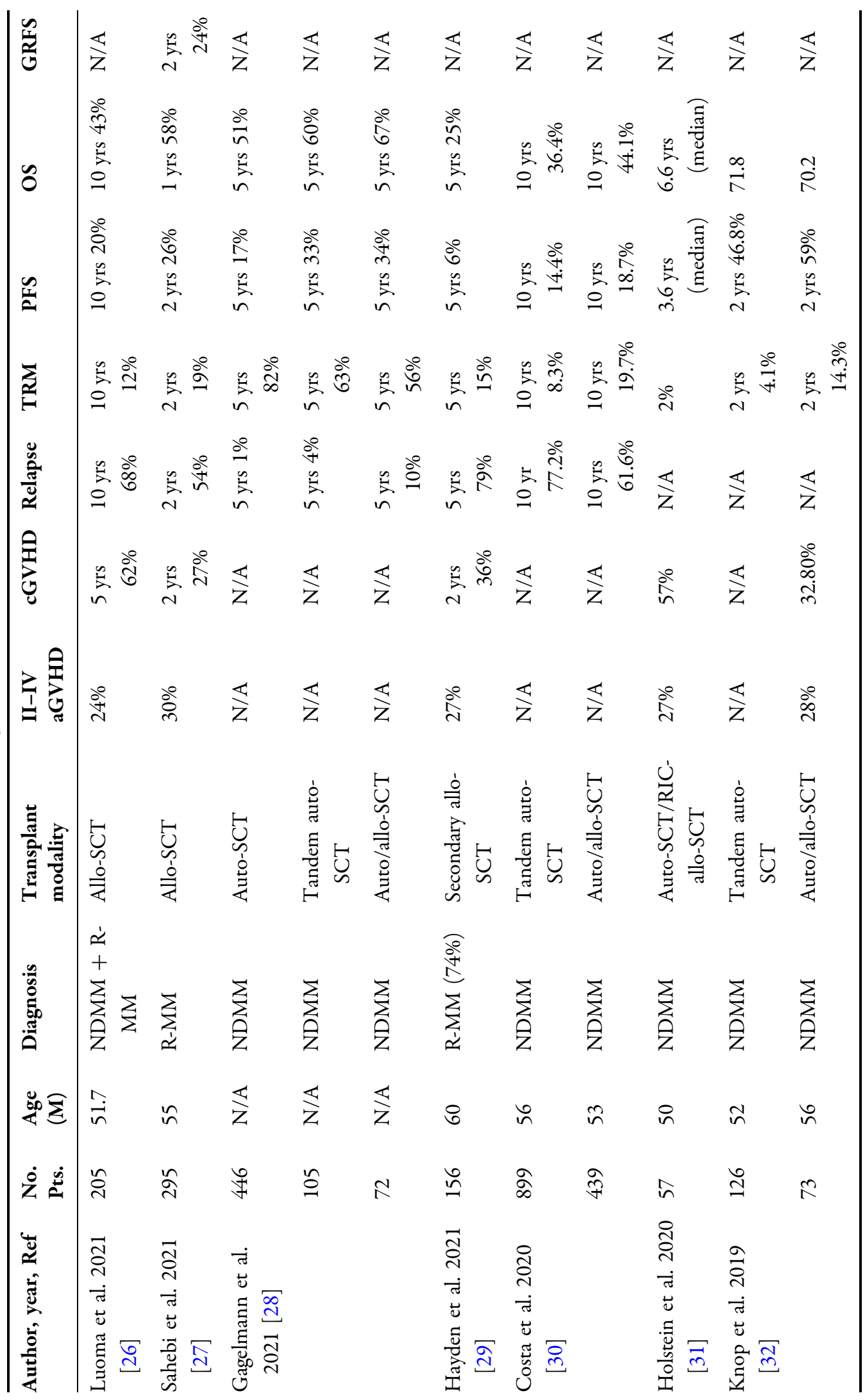




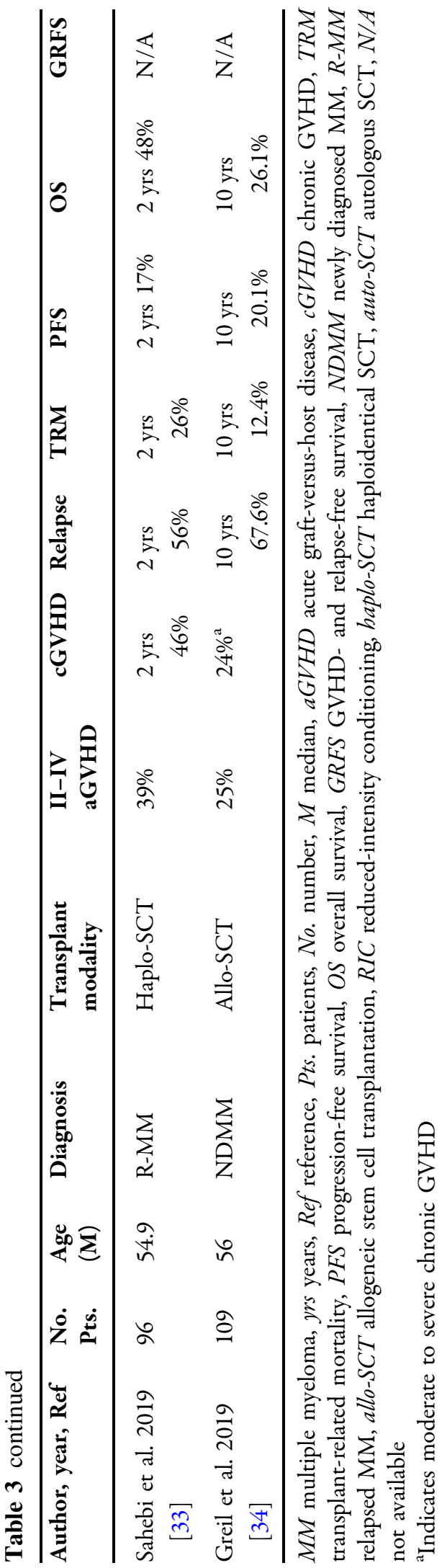

assigned to a group receiving melphalan alone (MEL group, $n=98$ ) and those receiving busulfan plus melphalan (BU/MEL group, $n=104$ ). The authors reported a median PFS of 43.5 months and 64.7 months for the MEL and BU/MEL groups, respectively. Although several researchers have demonstrated favorable survival outcomes with BU/MEL and carmustine/ MEL conditioning compared with those of high-dose MEL (HDM), HDM $\left(200 \mathrm{mg} / \mathrm{m}^{2}\right)$ has remained the recommended conditioning regimen for TE patients with NDMM [2-4, 41]. In our opinion, new multicenter randomized studies are needed to elucidate whether BU/ MEL and carmustine/MEL could become a new standard of care in the future.

Consolidation and Maintenance Therapy Consolidation or maintenance therapy can maximize the benefit of auto-SCT by prolonging PFS from the initial diagnosis $[12,43,45]$. The approaches for consolidation include bortezomib alone or plus other agents such as VTD and VRD, and for maintenance include lenalidomide [44, 52], bortezomib (especially for patients with high-risk cytogenetics), and ixazomib. However, thalidomide was not recommended [2-4, 41].

Recent advances in consolidation and maintenance therapy have mainly focused on DARA and ixazomib. Voorhees et al. [45] showed that the depth of response in patients with TE NDMM could be improved by D-RVD consolidation, with no new safety concerns. Moreau et al. [12] found that the risk of disease progression or death was significantly reduced after DARA maintenance every 8 weeks for 2 years compared with observation only. Data obtained from the oral ixazomib maintenance following autologous stem cell transplantationMM3 study demonstrate a significantly higher rate of deepening responses with ixazomib versus placebo maintenance as well as a correlation of deepening response with prolonged PFS [43]. Therefore, DARA or ixazomib maintenance could prolong PFS and represent a new option for maintenance therapy after auto-SCT in patients with NDMM [66]. 


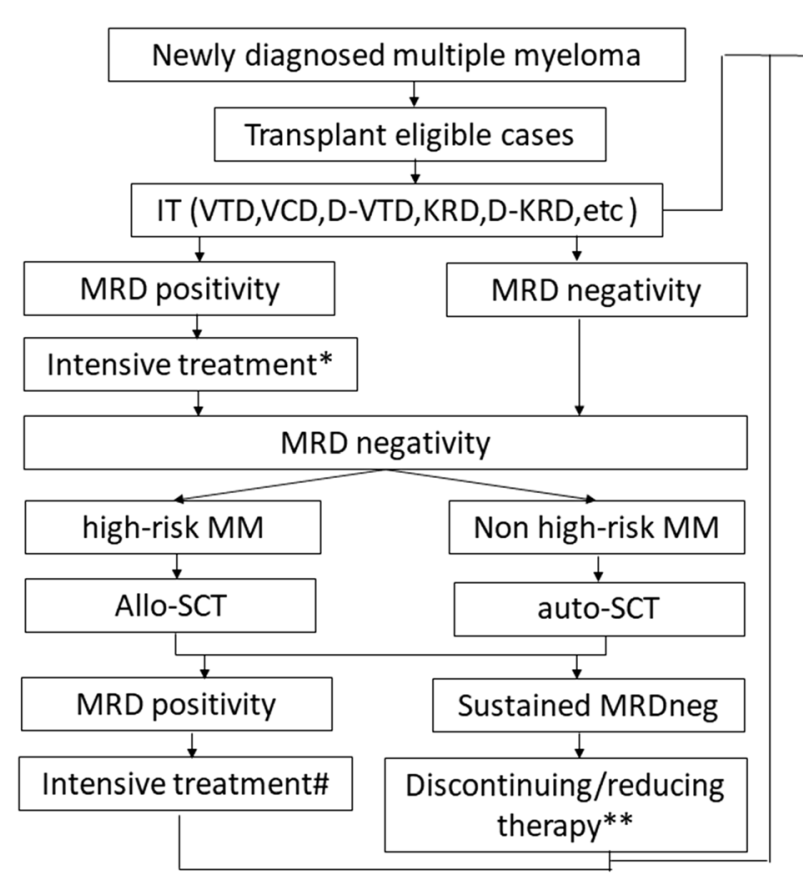

Fig. 1 Proposed algorithm for cellular therapies to treat MM and probability of MRD-directed therapy. $M M$ multiple myeloma, $M R D$ minimal residual disease, IT induction therapy, $K R D$ carfilzomib, lenalidomide, dexamethasone, VTD bortezomib, thalidomide, and dexamethasone, $V C D$ bortezomib, cyclophosphamide, and dexamethasone, $D-V T D$ daratumumab plus VTD, KRD carfilzomib, lenalidomide, and dexamethasone, $D-K R D$

\section{Salvage Auto-SCT}

According to the current literature [2-4, 41], salvage auto-SCT is recommended for patients whose disease was controlled by the first autoSCT for 18 months or longer. In addition, salvage or delayed auto-SCT could also be used as consolidation in first relapse for those choosing not to proceed to auto-SCT initially. For patients with DARA-refractory MM, one study reported median PFS and OS of 7.2 and 19.3 months, respectively, for an entire patient cohort receiving salvage auto-SCT [67]. The authors showed that factors including younger age, better performance status, low-risk GEP70 gene expression profile, and longer time interval from initial MM diagnosis/initial auto-SCT to salvage auto-SCT were associated with improved survival. In the era of novel agent therapy, the benefit of salvage auto-SCT was further confirmed in the German randomized

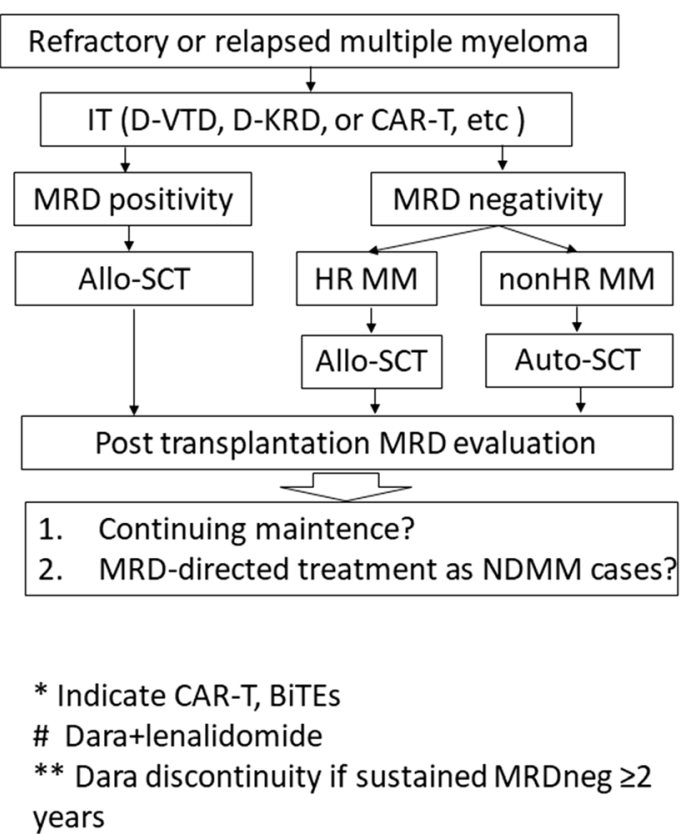

daratumumab plus KRD, allo-SCT allogeneic stem cell transplantation, auto-SCT autologous stem cell transplantation, MRDneg negative MRD, NDMM newly diagnosed MM, HR-MM high-risk MM, BiTEs bispecific T-cell engagers, Dara daratumumab. "Indicates that patients with standard-risk MM at diagnosis should not be treated according to MRD status

myeloma multicenter group phase III ReLApsE trial [61].

More recently, data from the Center for International Blood and Marrow Transplant Research registry suggested that patients who received maintenance regimens, including lenalidomide $(42 \%)$, pomalidomide $(13 \%)$, and bortezomib (13\%), after salvage auto-SCT showed superior outcomes, including non-relapse mortality (NRM; $2 \%$ vs. 9.9\%, $P<0.01$ ), relapse $(70.2 \%$ vs. $80.3 \%, P<0.01)$, PFS $(27.8 \%$ vs. $9.8 \%, P<0.01)$, and OS $(54 \%$ vs. $30.9 \%$, $P<0.01$ ), at 5 years compared to the no-maintenance group [56]. Available data supported the notion that maintenance was also recommended for patients receiving salvage auto-SCT $[2-4,41]$.

In summary, auto-SCT remains an important part of therapy for patients with NDMM and relapsing MM (Table 1). The available novel 


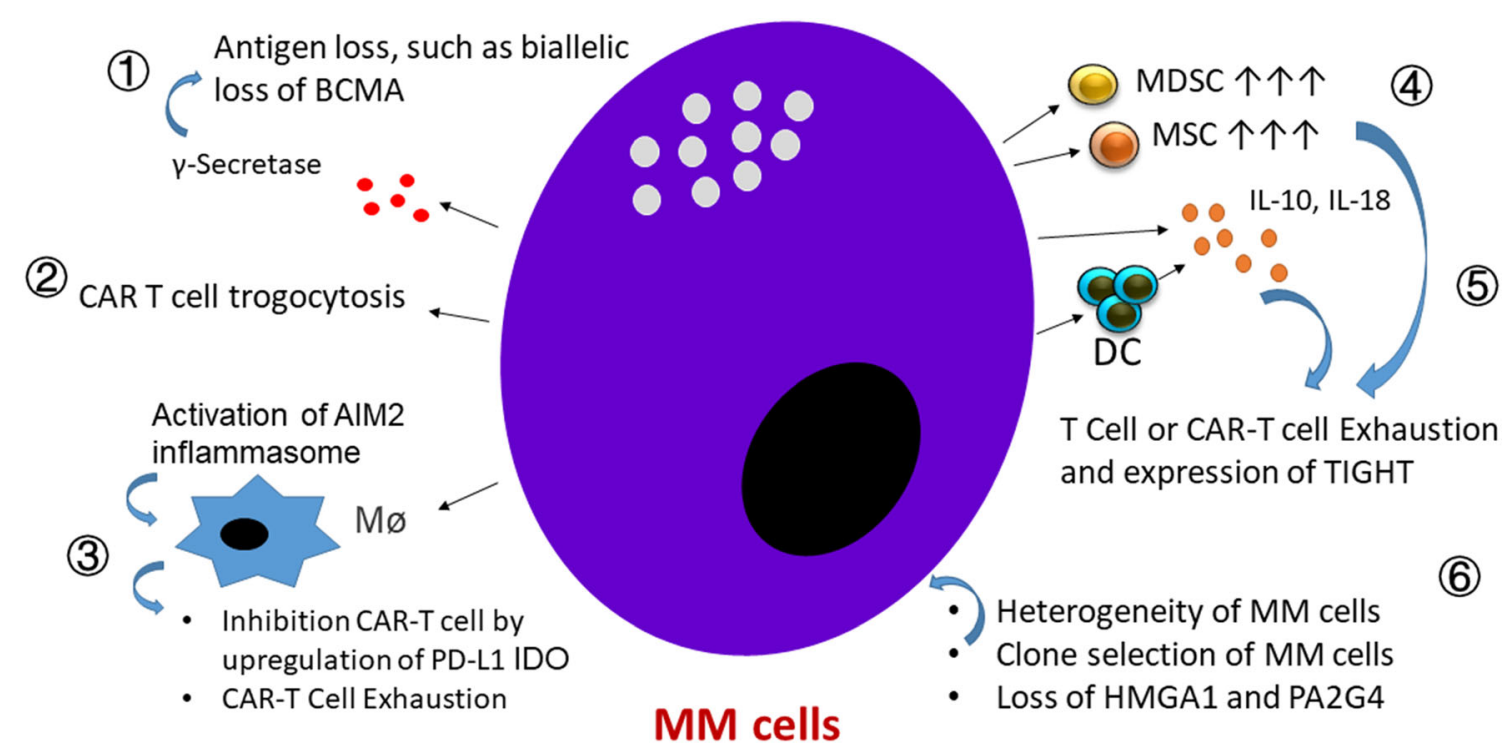

Fig. 2 Underlying mechanisms of CAR T-cell therapy resistance or relapse after transplantation. (1) BCMA could be actively cleaved from the tumor cell surface by the ubiquitous multi-subunit $\gamma$-secretase complex; (2) reversible antigen loss could be provoked by CAR T-cell trogocytosis; (3) inhibition of CAR T-cell function by macrophages; (4) MDSC and MSC as well as (5) IL-10 and IL-18 in bone

agents have been incorporated into induction, conditioning, consolidation, and maintenance regimens in relation to auto-SCT, which offered both PFS and OS benefits, even in patients with high-risk disease [38, 45, 60, 68-70]. The role, timing, and outcomes of auto-SCT will continue to be updated and improved as next-generation novel therapies continue to be developed and as our ability to detect MRD continues to improve.

\section{CAR T-Cell Therapy}

CAR T-cell therapy has achieved significant success in the treatment of $\mathrm{R} / \mathrm{R} \mathrm{MM}$ both in China and in other countries of the world (Table 2) [6, 14-25, 71-73]. At present, at least 600 patients with $\mathrm{R} / \mathrm{R} \mathrm{MM}$ who received CAR T-cell therapy have been reported $[6,14-25,71-73]$. The targeted antigens included B-cell maturation antigen (BCMA), CD38, and CD19, although preclinical and clinical trials on other antigens such as CD138, CD56, signaling lymphocyte activation molecule F7 marrow microenvironment could induce T-cell or CAR T-cell exhaustion; (6) loss of HMGA and PA2G4 could promote proliferation, migration, and adhesion abilities of MM cells. CAR T-cell chimeric antigen receptor T cell, $M \emptyset$ macrophage, $M D S C$ myeloid-derived suppressor cells, $M S C$ mesenchymal stem cells, $D C$ dendritic cells, $I L-10$ interleukin-10

(SLAMF7), natural killer group 2 member D (NKG2D) [74], and orphan G protein-coupled receptor class $\mathrm{C}$ group 5 member $\mathrm{D}$ (GPRC5D) were ongoing. A fludarabine and cyclophosphamide regimen was routinely used for lymphodepletion in nearly all publications. The overall response (OR) and CR rates after CAR T-cell therapy ranged from $73 \%$ to $100 \%$ and from $33 \%$ to $72 \%$, respectively. The cytokine release syndrome (CRS) rate ranged from $71 \%$ to $100 \%$, and 1 -year PFS ranged from $50 \%$ to $77 \%$. Overall, current CAR T-cell therapy for patients with $\mathrm{R} / \mathrm{R}$ MM showed a remarkably high OR rate, but durable response has not yet been observed [6, 14-25, 71-73]. Therefore, some questions still remain in this field: first, the specific mechanisms underlying relapse and immune escape; second, how to decrease the incidence of CAR T-cell toxicity and determine the best treatment; and third, how to deal with the issue on CAR T-cell access and cost. Apart from CAR T-cell therapy for BCMA, both belantamab mafodotin, an immunoconjugate targeting BCMA, and bispecific T-cell engager, a 
BiTE $^{\circledR}$ molecule binding BCMA on MM cells and CD3 on $\mathrm{T}$ cells, represent novel strategies for R/R MM [75, 76].

\section{Allo-SCT}

Allo-SCT remains a curative treatment for patients with hematological disease, particularly in the era where everyone has a transplant donor because of the wide application of haploidentical allograft $[77,78]$. Progress has been made in recent years (Table 3) [26-34, 58, 79-85]; although allo-SCT for MM has not been routinely recommended, it might be considered in select high-risk patients or in the context of a clinical trial [2-4]. In a phase 3 trial, Knop et al. [32] compared the outcomes of patients with NDMM with $\operatorname{del}(13 q)$ who received either tandem auto-SCT $(n=199)$ or auto-SCT followed by reduced-intensity conditioning allo-SCT (auto-/allo-SCT, $n=126$ ). After a median follow-up of 91 months, patients in the auto-/allo-SCT group experienced longer PFS (34.5 vs. 21.8 months, $P=0.003$ ) but higher 2 -year NRM $(14.3 \%$ vs. $4.1 \%, P=0.008)$ compared to those in the auto-SCT group. Subgroup analysis showed that treating patients harboring both del(13q) and del(17p) with auto-/alloSCT $(n=19)$ achieved longer median PFS (37.5 vs. 6.1 months, $P=0.0002)$ and $O S(61.5$ vs. 23.4 months, $P=0.032$ ) compared to treatment with tandem auto-SCT $(n=6)$. These findings suggested that auto-/allo-SCT significantly extended PFS versus tandem auto-SCT in del(13q) MM, and indicate some survival benefit for first-line allo-SCT in high-risk MM.

More recently, Costa et al. [30] performed a pooled analysis to compare the outcomes between tandem auto-SCT $(n=899)$ and auto-/ allo-SCT $(n=439)$ after IT based on individual patient data from four clinical trials. After a median follow-up of 118.5 months for survivors, the authors observed that patients who underwent auto-/allo-SCT had lower 10-year NRM $(8.3 \%$ vs. $19.7 \%, P<0.001)$ and risk of relapse $(61.6 \%$ vs. $77.2 \%, P<0.001)$ and better PFS (HR 0.84, $P=0.004$ ) and OS (HR 0.84, $P=0.02)$. This study suggested that the existence of graft-versus-myeloma after allograft could improve outcomes and cure a subset of patients.

Currently, the choice of indications for alloSCT in patients with high-risk MM or R/R MM is fairly significant $[26-28,32,34,79]$. It was expected that the discovery of new biomarkers that could be used to identify patients who would benefit from allograft would lead to a greater number of cases that would be cured, not just those cases with high-risk MM, such as $\operatorname{del}(17 p)$ patients and those who experienced early relapse after drug treatment with or without auto-SCT (Fig. 1).

\section{CHALLENGES WITH CELLULAR IMMUNOTHERAPIES}

\section{How to Cope with Relapse After Auto-SCT or CAR T-Cell Resistance}

Understanding the mechanisms of relapse after either transplantation or CAR T-cell therapy might provide novel insight into the prevention of recurrence [35, 86-90]. Available reports in the literature suggest several mechanisms [22, 88, 91, 92]: First, CARs could provoke reversible antigen loss through trogocytosis, which leads to decreased target density on tumor cells and abated T-cell activity by promoting fratricide T-cell killing and T-cell exhaustion [93]. Second, CAR T-cell therapy could induce the phenotype switch of the macrophages by upregulating the expression of programmed death ligand 1 and indoleamine 2,3-dioxygenase, consequently inhibiting the cytotoxicity of CAR $\mathrm{T}$ cells and proliferation of activated $T$ cells [94]. Other mechanisms for CAR T resistance included CAR T-cell exhaustion, release of interleukin-10 (IL-10) and IL-18 by $\mathrm{MM}$ cells, and clone selection of MM cells (Fig. 2). Strategies for CAR T-cell therapy resistance included the following $[89,90,95,96]$ : (i) cooperative killing and combinatorial targeting to augment tumor responses to immunotherapy; (ii) enhanced antitumor effects of CAR-T therapy by combination with blockade of the AIM2 inflammasome and $\alpha 1$ $\mathrm{AR}$; (iii) simultaneous application of anti-BCMA CAR-T with lenalidomide; (iv) treating R/R MM 
patients with CAR-T-cell plus immune checkpoints inhibitors; (vi) novel CAR-T design [89, 90, 96, 97], including SLAMF7 CAR T cells, CD126 CAR $\mathrm{T}$ cells, dual-specific, trimeric APRIL-based CAR T cells [98], and CD229specific CAR T cells, as well as the engineering of BCMA/CS1 OR-gate CAR T-cells; (vii) the possibility that CAR natural killer cells might be less toxic and present better anti-MM effects [74].

\section{Could MRD-Directed Therapy be Successfully Used for MM Patients?}

Currently, MRD has been routinely used for response evaluation and prediction of disease progression in patients with MM [7, 36-39]. Recent advances provided promising results showed that MRD-directed therapy could further improve the survival of patients with MM. For example, in a multicenter, multinational, retrospective study enrolling 400 patients with MRD monitoring during front-line therapy, Martinez-Lopez et al. [99] reported median PFS of 104 and 45 months for patients achieving MRD negativity at any point and those with persistent MRD positivity, respectively $(P<0.0001)$. The authors also observed that a treatment change based on MRD significantly prolonged PFS in comparison with cases in which MRD results were not acted upon (mPFS 104 vs. 62 months, $P=0.005$ ). During maintenance, stopping therapy in patients with MRD negativity on at least one occasion did not alter PFS. Impressively, intensification or change of therapy for patients with a positive MRD $(n=43)$ resulted in better PFS compared to those in whom no adjustment was made $(n=171)$ (mPFS NA vs. 39 months, $P=0.02$ ). These data suggest that MRD is useful in guiding clinical decisions during initial therapy and has a positive impact on PFS in MM patients, similar to MRD-directed therapy in patients with acute leukemia [100].

Although the available preliminary data remain to be confirmed in prospective randomized clinical trials, these studies have opened a new dimension for the use of MRD in MM [100-103]. Therefore, we propose an algorithm for MRD-directed therapy of patients with MM, which might be helpful for outcome improvement (Fig. 1).

\section{How Cellular Immunotherapies Should be Combined with Other Methods for MM}

Over the past few years, a number of novel methods have been developed, such as CC93269, a bispecific antibody that recognizes both BCMA and CD3e, allogeneic CAR T cells [104]. More recently, an open-label, single-arm, phase 1 study enrolled patients $(n=157)$ with MM who were relapsed, refractory, or intolerant to established therapies. Teclistamab (a bispecific antibody that binds BCMA and CD3 to redirect $\mathrm{T}$ cells to $\mathrm{MM}$ cells) was administered with step-up dosing for $38.4 \mu \mathrm{g} / \mathrm{kg}$ or higher doses. Among response-evaluable patients treated at the recommended phase 2 dose $(n=40)$, the OR was $65 \%$, and $58 \%$ achieved a very good partial response or better [105]. These data suggest that teclistamab is a novel treatment approach for $\mathrm{R} / \mathrm{R} \mathrm{MM}$ with durable responses and is well tolerated.

With regard to the combination of CAR T-cell therapy and allo-SCT, Qian et al. [73] presented the case of a heavily pretreated young patient with relapsed extramedullary $\mathrm{MM}$ (EMM) and refractoriness to bortezomib, ixazomib, lenalidomide, auto-SCT, and DARA, and indicated that myeloablative haploidenticalSCT as salvage treatment for relapse after CAR T-cell therapy targeting BCMA was feasible. The feasibility of combining CAR T cells with autoSCT for MM has also been reported by other researchers [106, 107].

Considering the contemporary literature collectively $[73,106,107]$, the promising results regarding the effects of anti-BCMA CAR T-cell therapy and allo-SCT may provide a proof of principle for patients with EMM [73]. Therefore, for patients with $\mathrm{MM}$, particular $\mathrm{R} / \mathrm{R} \mathrm{MM}$, prospective multicenter studies are needed to address the potential for combining CAR-T-cell therapy, auto-SCT, or allo-SCT with novel methods to improve outcomes. 


\section{Key Points}

- Auto-SCT remains the standard of care for TE patients with NDMM. The application of novel targeted therapies, such as DARA and ixazomib, in IT and consolidation as well as maintenance therapy further improves transplant outcomes.

- CAR T-cell therapy has been successfully used for the treatment of $\mathrm{R} / \mathrm{R}$ MM. The preliminary results of CAR T-cell bridging to SCT for patients with R/R MM are promising.

- Long-term follow-up suggests that allo-SCT can provide an opportunity for curing a subset of MM patients.

- In the era of new targeted therapies, MRDdirected treatment or intervention represents an important step for realizing precision medicine in patients with MM.

\section{Questions Remaining to be Answered}

- The best regimen for induction therapy or consolidation therapy or maintenance

- The best conditioning regimen for auto-SCT

- The indications for allo-SCT in patients with NDMM or R/R MM

- How to define the cases that will be cured by allo-SCT

- How to further elucidate the underlying mechanisms of CAR T-cell therapy resistance or relapse after transplantation

- How to enhance the anti-myeloma activity of CAR T-cell therapy

- Whether multicenter prospective studies are needed to confirm the feasibility and efficiency of CAR T-cell therapy bridging to SCT for patients with $\mathrm{R} / \mathrm{R} \mathrm{MM}$

- Whether haploidentical allograft can be successfully used for MM treatment

- Whether prospective, randomized studies are needed to confirm MRD-directed therapy in the field of MM

- Other issues, such as how to find novel targets for treatment of MM.

\section{FUTURE DIRECTIONS}

Recent advances in cellular immunotherapies [14-25] such as auto-SCT, allo-SCT, and CAR T- cell therapy [26-34] have to a certain extent changed their position in MM treatment as well as the landscape of $\mathrm{MM}$, especially $\mathrm{R} / \mathrm{R} \mathrm{MM}$. In the future, we will see the following advances. First, the combination of auto-SCT, allo-SCT, and CAR T-cell therapy as well as the combination of these approaches with other methods, including DARA and ixazomib, could enable the possibility of long-term PFS for a greater number of $\mathrm{R} / \mathrm{R}$ patients with $\mathrm{MM}$ who previously experienced poor outcomes. Second, the improvement in allo-SCT, especially haplo-SCT, could offer the possibility of a curative clinical outcome for a small number of patients with NDMM. Third, multicenter randomized clinical trials are needed to compare the outcomes of $\mathrm{R} / \mathrm{R} \mathrm{MM}$ cases treated with either CAR T-cell therapy or other targeted therapies, such as belantamab mafodotin and bispecific T-cell engager. Overall, further elucidation of the mechanisms of relapse and resistance to CAR T cells and auto-SCT/allo-SCT, the discovery of new biomarkers to direct therapy, and the design of new approaches for MM treatment, such as NKG2D-CAR-transduced natural killer cells $[74,90]$ and a novel CD38/CD3 bispecific T-cell engager [108], would help us improve outcomes through the realization of precision medicine for treating patients with MM.

\section{ACKNOWLEDGEMENTS}

Funding. This work was partly supported by Grants from the Beijing Municipal Science and Technology Commission (Z181100009618032).

Authorship. All named authors meet the International Committee of Medical Journal Editors (ICMJE) criteria for authorship for this article, take responsibility for the integrity of the work as a whole, and have given their approval for this version to be published.

Author contributions. Ying-Jun Chang designed the study; Zhi-Ling Yan and Yue-Wen Wang collected data; Ying-Jun Chang, Zhi-Ling Yan and Yue-Wen Wang analyzed the data and drafted the manuscript; all authors contributed 
to data interpretation, manuscript preparation, and approval of the final version.

Disclosures. Ying-Jun Chang, Yue-Wen Wang and Zhi-Ling Yan all have nothing to disclose.

Compliance with ethics guidelines. This review was prepared in accordance with ethics guidelines and the modified Helsinki Declaration. This article is based on previously conducted studies and does not contain any new studies with human participants or animals performed by any of the authors.

Open Access. This article is licensed under a Creative Commons Attribution-NonCommercial 4.0 International License, which permits any non-commercial use, sharing, adaptation, distribution and reproduction in any medium or format, as long as you give appropriate credit to the original author(s) and the source, provide a link to the Creative Commons licence, and indicate if changes were made. The images or other third party material in this article are included in the article's Creative Commons licence, unless indicated otherwise in a credit line to the material. If material is not included in the article's Creative Commons licence and your intended use is not permitted by statutory regulation or exceeds the permitted use, you will need to obtain permission directly from the copyright holder. To view a copy of this licence, visit http://creativecommons.org/licenses/by$\mathrm{nc} / 4.0 /$.

\section{REFERENCES}

1. van de Donk NWCJ, Pawlyn C, Yong KL. Multiple myeloma. The Lancet. 2021;397:410-27.

2. Dimopoulos MA, Moreau P, Terpos E, et al. Multiple myeloma: EHA-ESMO clinical practice guidelines for diagnosis, treatment and follow-up(dagger). Ann Oncol. 2021;32:309-22.

3. Sive J, Cuthill K, Hunter H, et al. Guidelines on the diagnosis, investigation and initial treatment of myeloma: a British Society for haematology/UK myeloma forum guideline. Br J Haematol. 2021;193: 245-68.

4. Mikhael J, Ismaila N, Cheung MC, et al. Treatment of multiple myeloma: ASCO and CCO joint clinical practice guideline. J Clin Oncol. 2019;37:1228-63.

5. Stadtmauer EA, Pasquini MC, Blackwell B, et al. Autologous transplantation, consolidation, and maintenance therapy in multiple myeloma: results of the BMT CTN 0702 trial. J Clin Oncol. 2019;37: 589-97.

6. Wang D, Wang J, Hu G, et al. A phase 1 study of a novel fully human BCMA-targeting CAR (CT103A) in patients with relapsed/refractory multiple myeloma. Blood. 2021;137:2890-901.

7. Diamond B, Korde N, Lesokhin AM, et al. Dynamics of minimal residual disease in patients with multiple myeloma on continuous lenalidomide maintenance: a single-arm, single-centre, phase 2 trial. Lancet Haematol. 2021;8:e422-32.

8. Roussel M, Moreau P, Hebraud B, et al. Bortezomib, thalidomide, and dexamethasone with or without daratumumab for transplantation-eligible patients with newly diagnosed multiple myeloma (CASSIOPEIA): health-related quality of life outcomes of a randomised, open-label, phase 3 trial. Lancet Haematol. 2020;7:e874-83.

9. Tacchetti P, Pantani L, Patriarca F, et al. Bortezomib, thalidomide, and dexamethasone followed by double autologous haematopoietic stem-cell transplantation for newly diagnosed multiple myeloma (GIMEMA-MMY-3006): long-term follow-up analysis of a randomised phase 3, open-label study. Lancet Haematol. 2020;7:e861-73.

10. Usmani SZ, Hoering A, Ailawadhi S, et al. Bortezomib, lenalidomide, and dexamethasone with or without elotuzumab in patients with untreated, high-risk multiple myeloma (SWOG-1211): primary analysis of a randomised, phase 2 trial. Lancet Haematol. 2021;8:e45-54.

11. Facon T, Kumar SK, Plesner T, et al. Daratumumab, lenalidomide, and dexamethasone versus lenalidomide and dexamethasone alone in newly diagnosed multiple myeloma (MAIA): overall survival results from a randomised, open-label, phase 3 trial. Lancet Oncol. 2021;22:1582-96.

12. Moreau P, Hulin C, Perrot A, et al. Maintenance with daratumumab or observation following treatment with bortezomib, thalidomide, and dexamethasone with or without daratumumab and autologous stem-cell transplant in patients with newly diagnosed multiple myeloma (CASSIOPEIA): an open-label, randomised, phase 3 trial. Lancet Oncol. 2021;22:1378-90. 
13. Munshi PN, Vesole DH, St Martin A, et al. Outcomes of upfront autologous hematopoietic cell transplantation in patients with multiple myeloma who are 75 years old or older. Cancer. 2021;127:4233-9.

14. Gagelmann N, Riecken K, Wolschke C, et al. Development of CAR-T cell therapies for multiple myeloma. Leukemia. 2020;34:2317-32.

15. Yan L, Qu S, Shang J, et al. Sequential CD19 and BCMA-specific CAR T cell treatment elicits sustained remission of relapsed and/or refractory myeloma. Cancer Med. 2021;10:563-74.

16. Munshi NC, Anderson LD Jr, Shah N, et al. Idecabtagene vicleucel in relapsed and refractory multiple myeloma. N Engl J Med. 2021;384:705-16.

17. Berdeja JG, Madduri D, Usmani SZ, et al. Ciltacabtagene autoleucel, a B-cell maturation antigen-directed chimeric antigen receptor $\mathrm{T}$ cell therapy in patients with relapsed or refractory multiple myeloma (CARTITUDE-1): a phase 1b/2 open-label study. Lancet. 2021;398:314-24.

18. Zhang M, Zhou L, Zhao H, et al. Risk factors associated with durable progression-free survival in patients with relapsed or refractory multiple myeloma treated with anti-BCMA CAR T cell therapy. Clin Cancer Res. 2021. https://doi.org/10.2139/ ssrn.3857669.

19. Mei H, Li C, Jiang H, et al. A bispecific CAR-T cell therapy targeting BCMA and CD38 in relapsed or refractory multiple myeloma. J Hematol Oncol. $2021 ; 14: 161$

20. Deng H, Liu M, Yuan T, et al. Efficacy of humanized anti-BCMA CAR $\mathrm{T}$ cell therapy in relapsed/refractory multiple myeloma patients with and without extramedullary disease. Front Immunol. 2021;12: 720571.

21. Raje N, Berdeja J, Lin Y, et al. Anti-BCMA CAR T cell therapy bb2121 in relapsed or refractory multiple myeloma. N Engl J Med. 2019;380:1726-37.

22. Yan Z, Cao J, Cheng $\mathrm{H}$, et al. A combination of humanised anti-CD19 and anti-BCMA CAR T cells in patients with relapsed or refractory multiple myeloma: a single-arm, phase 2 trial. Lancet Haematol. 2019;6:e521-9.

23. Xu J, Chen LJ, Yang SS, et al. Exploratory trial of a biepitopic CAR T-targeting B cell maturation antigen in relapsed/refractory multiple myeloma. Proc Natl Acad Sci USA. 2019;116:9543-51.

24. Brudno JN, Maric I, Hartman SD, et al. T cells genetically modified to express an anti-B-cell maturation antigen chimeric antigen receptor cause remissions of poor-prognosis relapsed multiple myeloma. J Clin Oncol. 2018;36:2267-80.

25. Zhao WH, Liu J, Wang BY, et al. A phase 1, openlabel study of LCAR-B38M, a chimeric antigen receptor $\mathrm{T}$ cell therapy directed against $\mathrm{B}$ cell maturation antigen, in patients with relapsed or refractory multiple myeloma. J Hematol Oncol. 2018;11:141.

26. Luoma S, Silvennoinen R, Rauhala A, et al. Longterm outcome after allogeneic stem cell transplantation in multiple myeloma. Ann Hematol. 2021;100:1553-67.

27. Sahebi F, Eikema DJ, Koster L, et al. Post-transplantation cyclophosphamide for graft-versus-host disease prophylaxis in multiple myeloma patients who underwent allogeneic hematopoietic cell transplantation: first comparison by donor type. A study from the chronic malignancies working party of the European Society for Blood and Marrow Transplantation. Transplant Cell Ther. 2021. https://doi.org/10.1016/j.jtct.2021.09.008.

28. Gagelmann N, Eikema DJ, de Wreede LC, et al. Upfront stem cell transplantation for newly diagnosed multiple myeloma with del $(17 \mathrm{p})$ and $t(4 ; 14)$ : a study from the CMWP-EBMT. Bone Marrow Transplant. 2021;56:210-7.

29. Hayden PJ, Eikema DJ, de Wreede LC, et al. Second allogeneic transplants for multiple myeloma: a report from the EBMT chronic malignancies working party. Bone Marrow Transplant. 2021;56: 2367-81.

30. Costa LJ, Iacobelli S, Pasquini MC, et al. Long-term survival of $1338 \mathrm{MM}$ patients treated with tandem autologous vs. autologous-allogeneic transplantation. Bone Marrow Transplant. 2020;55:1810-6.

31. Holstein SA, Suman VJ, Owzar K, et al. Long-term follow-up of CALGB (alliance) 100001: autologous followed by nonmyeloablative allogeneic transplant for multiple myeloma. Biol Blood Marrow Transplant. 2020;26:1414-24.

32. Knop S, Engelhardt M, Liebisch P, et al. Allogeneic transplantation in multiple myeloma: long-term follow-up and cytogenetic subgroup analysis. Leukemia. 2019;33:2710-9.

33. Sahebi F, Garderet L, Kanate AS, et al. Outcomes of haploidentical transplantation in patients with relapsed multiple myeloma: an EBMT/CIBMTR report. Biol Blood Marrow Transplant. 2019;25: $335-42$.

34. Greil C, Engelhardt M, Ihorst G, et al. Allogeneic transplantation of multiple myeloma patients may allow long-term survival in carefully selected 
patients with acceptable toxicity and preserved quality of life. Haematologica. 2019;104:370-9.

35. Minnie SA, Kuns RD, Gartlan KH, et al. Myeloma escape after stem cell transplantation is a consequence of $\mathrm{T}$ cell exhaustion and is prevented by TIGIT blockade. Blood. 2018;132:1675-88.

36. Paiva B, Cedena MT, Puig N, et al. Minimal residual disease monitoring and immune profiling in multiple myeloma in elderly patients. Blood. 2016;127: 3165-74.

37. Diamond BT, Rustad E, Maclachlan K, et al. Defining the undetectable: The current landscape of minimal residual disease assessment in multiple myeloma and goals for future clarity. Blood Rev. 2021;46:100732.

38. Avet-Loiseau H, San-Miguel J, Casneuf $\mathrm{T}$, et al. Evaluation of sustained minimal residual disease negativity with daratumumab-combination regimens in relapsed and/or refractory multiple myeloma: analysis of POLLUX and CASTOR. J Clin Oncol. 2021;39:1139-49.

39. Kumar S, Paiva B, Anderson KC, et al. International Myeloma Working Group consensus criteria for response and minimal residual disease assessment in multiple myeloma. Lancet Oncol. 2016;17: e328-46.

40. Cavo M, Gay F, Beksac M, et al. Autologous haematopoietic stem-cell transplantation versus bortezomib-melphalan-prednisone, with or without bortezomib-lenalidomide-dexamethasone consolidation therapy, and lenalidomide maintenance for newly diagnosed multiple myeloma (EMN02/HO95): a multicentre, randomised, openlabel, phase 3 study. Lancet Haematol. 2020;7: e456-68.

41. Parrondo RD, Ailawadhi S, Sher T, Chanan-Khan AA, Roy V. Autologous stem-cell transplantation for multiple myeloma in the era of novel therapies. JCO Oncol Pract. 2020;16:56-66.

42. Barosi G, Gale RP. Is lenalidomide the standard-ofcare after an autotransplant for plasma cell myeloma? Leukemia. 2019;33:588-96.

43. Goldschmidt H, Dimopoulos MA, Rajkumar SV, et al. Deepening responses associated with improved progression-free survival with ixazomib versus placebo as posttransplant maintenance in multiple myeloma. Leukemia. 2020;34:3019-27.

44. Goldschmidt H, Mai EK, Durig J, et al. Responseadapted lenalidomide maintenance in newly diagnosed myeloma: results from the phase III GMMGMM5 trial. Leukemia. 2020;34:1853-65.
45. Voorhees PM, Kaufman JL, Laubach J, et al. Daratumumab, lenalidomide, bortezomib, and dexamethasone for transplant-eligible newly diagnosed multiple myeloma: the GRIFFIN trial. Blood. 2020;136:936-45.

46. Baertsch MA, Mai EK, Hielscher T, et al. Lenalidomide versus bortezomib maintenance after frontline autologous stem cell transplantation for multiple myeloma. Blood Cancer J. 2021;11:1.

47. Bygrave C, Pawlyn C, Davies F, et al. Early relapse after high-dose melphalan autologous stem cell transplant predicts inferior survival and is associated with high disease burden and genetically highrisk disease in multiple myeloma. Br J Haematol. 2021;193:551-5.

48. Cherniawsky HM, AlAhwal H, Mourad YA, et al. Mortality from multiple myeloma within one year following autologous stem cell transplantation: defining an ultra-high risk population. Clin Lymphoma Myeloma Leuk. 2021;21:476-82.

49. Giebel S, Sobczyk-Kruszelnicka M, Blamek S, et al. Tandem autologous hematopoietic cell transplantation with sequential use of total marrow irradiation and high-dose melphalan in multiple myeloma. Bone Marrow Transplant. 2021;56: 1297-304.

50. Giri S, Chen $\mathrm{Y}, \mathrm{Wu}$ J, et al. Reduction in late mortality among patients with multiple myeloma treated with autologous peripheral blood stem cell transplantation-a blood or marrow transplant survivor study report. Transplant Cell Ther. 2021;27(840):e1-7.

51. Gregersen H, Peceliunas V, Remes K, et al. Carfilzomib and dexamethasone maintenance following salvage ASCT in multiple myeloma: a randomised phase 2 trial by the nordic myeloma study group. Eur J Haematol. 2021. https://doi.org/10.1111/ejh. 13709.

52. Jackson GH, Davies FE, Pawlyn C, et al. Lenalidomide before and after autologous stem cell transplantation for transplant-eligible patients of all ages in the randomized, phase III. Myeloma XI trial Haematol. 2021;106:1957-67.

53. Jackson GH, Pawlyn C, Cairns DA, et al. Carfilzomib, lenalidomide, dexamethasone, and cyclophosphamide (KRdc) as induction therapy for transplant-eligible, newly diagnosed multiple myeloma patients (Myeloma XI+): interim analysis of an open-label randomised controlled trial. PLoS Med. 2021;18:e1003454.

54. Lemieux C, Muffly LS, Iberri DJ, et al. Outcomes after delayed and second autologous stem cell 
transplant in patients with relapsed multiple myeloma. Bone Marrow Transplant. 2021;56:2664-71.

55. Mai EK, Miah K, Bertsch U, et al. Bortezomib-based induction, high-dose melphalan and lenalidomide maintenance in myeloma up to 70 years of age. Leukemia. 2021;35:809-22.

56. Pasvolsky O, Yeshurun M, Fraser R, et al. Maintenance therapy after second autologous hematopoietic cell transplantation for multiple myeloma. A CIBMTR analysis. Bone Marrow Transplant. 2021. https://doi.org/10.1200/JCO.2021.39.15_suppl. 8022.

57. Skarbnik AP, Donato ML, Feinman R, et al. Safety and efficacy of consolidation therapy with ipilimumab plus nivolumab after autologous stem cell transplantation. Transplant Cell Ther. 2021;27: 391-403.

58. Tan JLC, Das T, Kliman D, et al. Evaluation of EuroFlow minimal residual disease measurement and donor chimerism monitoring following tandem auto-allogeneic transplantation for multiple myeloma. Bone Marrow Transplant. 2021;56: 1116-25.

59. Rosinol L, Oriol A, Rios R, et al. Bortezomib, lenalidomide, and dexamethasone as induction therapy prior to autologous transplant in multiple myeloma. Blood. 2019;134:1337-45.

60. Gay F, Musto P, Rota-Scalabrini D, et al. Carfilzomib with cyclophosphamide and dexamethasone or lenalidomide and dexamethasone plus autologous transplantation or carfilzomib plus lenalidomide and dexamethasone, followed by maintenance with carfilzomib plus lenalidomide or lenalidomide alone for patients with newly diagnosed multiple myeloma (FORTE): a randomised, open-label, phase 2 trial. Lancet Oncol. 2021. https://doi.org/10.1016/ S1470-2045(21)00535-0.

61. Goldschmidt H, Baertsch MA, Schlenzka J, et al. Salvage autologous transplant and lenalidomide maintenance vs. lenalidomide/dexamethasone for relapsed multiple myeloma: the randomized GMMG phase III trial ReLApsE. Leukemia. 2021;35: 1134-44.

62. Drayson MT, Bowcock S, Planche T, et al. Levofloxacin prophylaxis in patients with newly diagnosed myeloma (TEAMM): a multicentre, doubleblind, placebo-controlled, randomised, phase 3 trial. Lancet Oncol. 2019;20:1760-72.

63. Moreau P, Attal M, Hulin C, et al. Bortezomib, thalidomide, and dexamethasone with or without daratumumab before and after autologous stem-cell transplantation for newly diagnosed multiple myeloma (CASSIOPEIA): a randomised, open-label, phase 3 study. The Lancet. 2019;394:29-38.

64. Goldschmidt H, Mai EK, Nievergall E, et al. Addition of isatuximab to lenalidomide, bortezomib and dexamethasone as induction therapy for newly-diagnosed, transplant-eligible multiple myeloma patients: the phase III GMMG-HD7 trial. Blood. 2021;138(Supplement 1):463.

65. Bashir Q, Thall PF, Milton DR, et al. Conditioning with busulfan plus melphalan versus melphalan alone before autologous haemopoietic cell transplantation for multiple myeloma: an open-label, randomised, phase 3 trial. Lancet Haematol. 2019;6: e266-75.

66. Dimopoulos MA, Gay F, Schjesvold F, et al. Oral ixazomib maintenance following autologous stem cell transplantation (TOURMALINE-MM3): a double-blind, randomised, placebo-controlled phase 3 trial. The Lancet. 2019;393:253-64.

67. Yarlagadda L, Gundarlapalli S, Parikh R, et al. Salvage autologous stem cell transplantation in daratumumab-refractory multiple myeloma. Cancers (Basel). 2021. https://doi.org/10.3390/ cancers13164019.

68. Voorhees PM, Rodriguez C, Reeves B, et al. Daratumumab plus RVd for newly diagnosed multiple myeloma: final analysis of the safety run-in cohort of GRIFFIN. Blood Adv. 2021;5:1092-6.

69. Shah UA, Mailankody S. Emerging immunotherapies in multiple myeloma. BMJ. 2020;370:m3176.

70. Spencer A, Lentzsch S, Weisel K, et al. Daratumumab plus bortezomib and dexamethasone versus bortezomib and dexamethasone in relapsed or refractory multiple myeloma: updated analysis of CASTOR. Haematologica. 2018;103:2079-87.

71. Moreau P, Sonneveld P, Boccadoro M, et al. Chimeric antigen receptor $T$ cell therapy for multiple myeloma: a consensus statement from the European myeloma network. Haematologica. 2019;104: 2358-60.

72. Dhakal B, Hari PN, Usmani SZ, Hamadani M. Chimeric antigen receptor $\mathrm{T}$ cell therapy in multiple myeloma: promise and challenges. Bone Marrow Transplant. 2021;56:9-19.

73. Qian Y, Qian Z, Zhao X, et al. Successful treatment of relapsed/refractory extramedullary multiple myeloma with anti-BCMA CAR-T cell therapy followed by haploidentical hematopoietic stem cell transplantation: a case report and a review of the contemporary literature. Front Med (Lausanne). 2021;8:649824. 
74. Leivas A, Valeri A, Cordoba L, et al. NKG2D-CARtransduced natural killer cells efficiently target multiple myeloma. Blood Cancer J. 2021;11:146.

75. Lonial S, Lee HC, Badros A, et al. Belantamab mafodotin for relapsed or refractory multiple myeloma (DREAMM-2): a two-arm, randomised, openlabel, phase 2 study. Lancet Oncol. 2020;21:207-21.

76. Harrison SJ, Minnema MC, Lee HC, et al. A phase 1 first in human (FIH) study of AMG 701, an anti-Bcell maturation antigen (BCMA) half-life extended (HLE) BiTE ${ }^{\circledR}$ (bispecific T cell engager) molecule, in relapsed/refractory (RR) multiple myeloma (MM). Blood. 2020;136(Supplement 1):28-9.

77. Chang YJ, Zhao XY, Huang XJ. Granulocyte colonystimulating factor-primed unmanipulated haploidentical blood and marrow transplantation. Front Immunol. 2019;10:2516.

78. Fuchs EJ, McCurdy SR, Solomon SR, et al. HLA informs risk predictions after haploidentical stem cell transplantation with post-transplantation cyclophosphamide. Blood. 2021. https://doi.org/10. 1182/blood.2021013443.

79. Van Elssen C, van Gorkom G, Voorter C, et al. Haploidentical transplantation in patients with multiple myeloma making use of natural killer cell alloreactive donors. Ann Hematol. 2021;100:181-7.

80. Cowan AJ, Baldomero H, Atsuta Y, et al. The global state of hematopoietic cell transplantation for multiple myeloma: an analysis of the worldwide network of blood and marrow transplantation database and the global burden of disease study. Biol Blood Marrow Transplant. 2020;26:2372-7.

81. Gomez-Arteaga A, Shah GL, Baser RE, et al. Prognostic factors for postrelapse survival after ex vivo CD34(+)-selected (T Cell-Depleted) allogeneic hematopoietic cell transplantation in multiple myeloma. Biol Blood Marrow Transplant. 2020;26: 2040-6.

82. Groger M, Gagelmann N, Wolschke C, et al. Longterm results of prophylactic donor lymphocyte infusions for patients with multiple myeloma after allogeneic stem cell transplantation. Biol Blood Marrow Transplant. 2018;24:1399-405.

83. Htut M, D'Souza A, Krishnan A, et al. Autologous/ allogeneic hematopoietic cell transplantation versus tandem autologous transplantation for multiple myeloma: comparison of long-term postrelapse survival. Biol Blood Marrow Transplant. 2018;24: 478-85.

84. Kawamura K, Tsukada N, Kanda Y, et al. The role of allogeneic transplantation for multiple myeloma in the era of novel agents: a study from the Japanese society of myeloma. Biol Blood Marrow Transplant. 2018;24:1392-8.

85. Goldschmidt H, Lokhorst HM, Mai EK, et al. Bortezomib before and after high-dose therapy in myeloma: long-term results from the phase III HOVON-65/GMMG-HD4 trial. Leukemia. 2018;32: 383-90.

86. Shen YJ, Mishima Y, Shi J, et al. Progression signature underlies clonal evolution and dissemination of multiple myeloma. Blood. 2021;137:2360-72.

87. Holthof LC, van der Schans JJ, Katsarou A, et al. Bone marrow mesenchymal stromal cells can render multiple myeloma cells resistant to cytotoxic machinery of CAR T cells through inhibition of apoptosis. Clin Cancer Res. 2021;27:3793-803.

88. Pont MJ, Hill T, Cole GO, et al. gamma-Secretase inhibition increases efficacy of BCMA-specific chimeric antigen receptor T cells in multiple myeloma. Blood. 2019;134:1585-97.

89. Radhakrishnan SV, Luetkens T, Scherer SD, et al. CD229 CAR T cells eliminate multiple myeloma and tumor propagating cells without fratricide. Nat Commun. 2020;11:798.

90. Zah E, Nam E, Bhuvan V, et al. Systematically optimized BCMA/CS1 bispecific CAR-T cells robustly control heterogeneous multiple myeloma. Nat Commun. 2020;11:2283.

91. Da Via MC, Dietrich O, Truger M, et al. Homozygous BCMA gene deletion in response to anti-BCMA CAR T cells in a patient with multiple myeloma. Nat Med. 2021;27:616-9.

92. Samur MK, Fulciniti M, Aktas Samur A, et al. Biallelic loss of BCMA as a resistance mechanism to CAR $\mathrm{T}$ cell therapy in a patient with multiple myeloma. Nat Commun. 2021;12:868.

93. Hamieh M, Dobrin A, Cabriolu A, et al. CAR T cell trogocytosis and cooperative killing regulate tumour antigen escape. Nature. 2019;568:112-6.

94. Liu D, Xu X, Dai Y, et al. Blockade of AIM2 inflammasome or alpha1-AR ameliorates IL-1beta release and macrophage-mediated immunosuppression induced by CAR-T treatment. J Immunother Cancer. 2021. https://doi.org/10. 1136/jitc-2020-001466.

95. Amatya C, Pegues MA, Lam N, et al. Development of CAR T cells expressing a suicide gene plus a chimeric antigen receptor targeting signaling lymphocytic-activation molecule F7. Mol Ther. 2021;29:702-17. 
96. Mishra AK, Kemler I, Dingli D. Preclinical development of CD126 CAR-T cells with broad antitumor activity. Blood Cancer J. 2021;11:3.

97. Prommersberger S, Reiser M, Beckmann J, et al. CARAMBA: a first-in-human clinical trial with SLAMF7 CAR-T cells prepared by virus-free sleeping beauty gene transfer to treat multiple myeloma. Gene Ther. 2021. https://doi.org/10.1038/s41434021-00254-w.

98. Schmidts A, Ormhoj M, Choi BD, et al. Rational design of a trimeric APRIL-based CAR-binding domain enables efficient targeting of multiple myeloma. Blood Adv. 2019;3:3248-60.

99. Martinez-Lopez J, Alonso R, Wong SW, et al. Making clinical decisions based on measurable residual disease improves the outcome in multiple myeloma. J Hematol Oncol. 2021;14:126.

100. Yang W, Cai J, Shen S, et al. Pulse therapy with vincristine and dexamethasone for childhood acute lymphoblastic leukaemia (CCCG-ALL-2015): an open-label, multicentre, randomised, phase 3 , noninferiority trial. Lancet Oncol. 2021;22:1322-32.

101. Patel DA, Gopalakrishnan R, Engelhardt BG, et al. Minimal residual disease negativity and lenalidomide maintenance therapy are associated with superior survival outcomes in multiple myeloma. Bone Marrow Transplant. 2020;55:1137-46.

102. Oliva S, Bruinink DHO, Rihova L, et al. Minimal residual disease assessment by multiparameter flow cytometry in transplant-eligible myeloma in the
EMN02/HOVON $95 \mathrm{MM}$ trial. Blood Cancer J. 2021;11:106.

103. Oliva S, D’Agostino M, Boccadoro M, Larocca A. Clinical applications and future directions of minimal residual disease testing in multiple myeloma. Front Oncol. 2020;10:1.

104. Ramasamy K, Gay F, Weisel K, Zweegman S, Mateos MV, Richardson P. Improving outcomes for patients with relapsed multiple myeloma: challenges and considerations of current and emerging treatment options. Blood Rev. 2021;49:100808.

105. Usmani SZ, Garfall AL, van de Donk N, et al. Teclistamab, a B-cell maturation antigen x CD3 bispecific antibody, in patients with relapsed or refractory multiple myeloma (MajesTEC-1): a multicentre, open-label, single-arm, phase 1 study. Lancet. 2021;398:665-74.

106. Garfall AL, Stadtmauer EA, Hwang WT, et al. AntiCD19 CAR T cells with high-dose melphalan and autologous stem cell transplantation for refractory multiple myeloma. JCI Insight. 2018. https://doi. org/10.1172/jci.insight.120505.

107. Wu J, Meng F, Cao Y, et al. Sequential CD19/22 CAR $\mathrm{T}$ cell immunotherapy following autologous stem cell transplantation for central nervous system lymphoma. Blood Cancer J. 2021;11:131.

108. Fayon M, Martinez-Cingolani C, Abecassis A, et al. $\mathrm{Bi} 38-3$ is a novel CD38/CD3 bispecific T cell engager with low toxicity for the treatment of multiple myeloma. Haematologica. 2021;106:1193-7. 